\title{
As Problemáticas Éticas e Estéticas a Partir do Exemplo de uma Prática Teatral na Prisão
}

\author{
Marie Urban \\ Universidade de Aix-Marselha, França \\ Universidade de Hildesheim, Alemanha \\ Email: marie.urban.mrs@gmail.com
}

\section{Resumo}

A prática do teatro na prisão levanta a questão da participação de profissionais não profissionais em projetos artísticos. Este artigo é uma oportunidade para observar os vínculos entre questões éticas e estéticas, que estão no centro dos discursos sobre a participação, a partir do exemplo muito singular de produção artística nas prisões do coletivo independente de Berlim aufBruch ${ }^{1}$. Para fazer isso, gostaria de voltar ao processo que experimentei várias vezes com o diretor Adrian Figueroa, durante a realização de projetos de teatro e cinema com prisioneiros nas prisões de Plötzensee e Tegel em Berlin. O trabalho é baseado em oficinas de redação e entrevistas com prisioneiros. Nessa oportunidade, descrevo as estratégias de distanciamento implementadas durante esses projetos, a fim de desenvolver formas literárias próximas à autoficção, em que surge uma tensão entre a vida e a narrativa imaginária. Ao combinar uma abordagem teórica e prática, trata-se de transpor o obstáculo de evitar "expor" os prisioneiros e questionar, por um lado, a função social da arte que pode se afirmar como um espaço agonístico e, por outro lado, enfatizar os aspectos estéticos desses projetos que oscilam entre o espaço autêntico e simbólico. Nesta ocasião, podemos nos perguntar como os corpos encerrados em um lugar "absolutamente diferente" (Foucault) podem ser projetados em outro espaço.

Palavras-chave

Prática teatral. Teatro em prisão. Oficinas de escrita. Entrevistas.
Résumé

La pratique du théâtre en prison pose la question de la participation de personnes non professionnelles dans des projets artistiques. Cet article est l'occasion d'observer les liens entre les problématiques éthiques et esthétiques, qui sont au cœur des discours sur la participation, à partir de l'exemple très singulier de la production artistique en milieu carcéral du collectif indépendant berlinois aufBruch. Je souhaite pour cela revenir sur la démarche que j'ai expérimentée à plusieurs reprises avec le metteur en scène Adrian Figueroa, lors de la réalisation de projets de théâtre et de film avec des détenus dans les prisons de Plötzensee et de Tegel à Berlin. Le travail se base sur des ateliers d'écriture et des interviews réalisées avec les détenus. Je décris à cette occasion les stratégies de distanciation mises en place durant ces projets afin de développer des formes littéraires proches de l'autofiction, dans lesquels émerge une tension entre récit de vie et imaginaire. En mêlant une approche théorique et pratique, il s'agit, de discuter de l'écueil à éviter d'« exposer » les détenus, de questionner d'une part la fonction sociale de l'art pouvant s'affirmer comme un espace agonistique, et, d'autre part, de souligner les aspects esthétiques de ces projets qui oscillent entre espace authentique et symbolique. On pourra à cette occasion se demander comment les corps enfermés dans un lieu "absolument différent» (Foucault) peuvent être projetés dans un autre espace.

Mots-clés

Pratique théâtrale. Théâtre en prison. Ateliers d'écriture. Interviews.

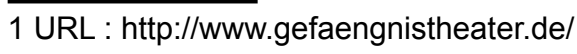




\section{A questão da participação}

O teatro de língua alemã está atualmente marcado por um aumento das práticas documentais que se manifestam de várias formas. Em alguns casos, fala-se de "teatro de pesquisa"1, porque às vezes uma longa pesquisa, criando um arquivo heterogêneo, pode estar no cerne do processo de criação teatral. É difícil descrever essas criações porque elas levam a realidade de diversas maneiras e também demonstram um "estado de espírito performativo", para retomar a expressão de Joseph Danan (Danan, 2016, p. 59). A posição dos artistas, que se tornam sociólogos ou jornalistas de investigação, também muda. Há também um aumento na participação de pessoas distantes do teatro em processos criativos. Esses participantes são, por sua vez, chamados de "testemunhas", "convidados"2, "especialistas do cotidiano"3, "intérpretes não profissionais" ou "pesquisadores associados"4. Estes diferentes termos refletem as diferentes formas de integrar essas pessoas. No entanto, muitas vezes é uma reflexão coletiva sobre os fenômenos sociais que são, então, revelados no palco. Os acontecimentos políticos recentes, particular-

1 O termo "teatro de pesquisa" é uma tradução do termo alemão "Researchtheater", que é cada vez mais usado pelos críticos, mas também por praticantes e dramaturgos: de 19 a 21 de novembro de 2015 realizaram-se o " 1 . Researchtheatertage" (primeiro dia dedicado ao teatro de pesquisa "no Deutsches Theater de Berlim").

2 Este é o caso do grupo She She Pop quando, por exemplo, eles convidam seus próprios pais para se apresentarem com eles no jogo do Testamento.

3 Tradução do termo "Experten des Alltags", introduzido pela prática de Rimini Protokoll, mas que agora é amplamente utilizado.

4 O psicólogo Günter Mey propôs durante o primeiro "Recherchethatertage" (referido acima) privilegiar a palavra "Mit-Forschenden" que poderia ser traduzida como "pesquisador associado ou co-pesquisador" em vez de "testemunhas" para qualificar os participantes como parte do processo criativo. mente após o aumento constante do número de requerentes de asilo na Alemanha desde 2015, também contribuíram para o surgimento de inúmeras peças ou espectáculos em que os refugiados são levados à cena. Difícil determinar os fundamentos dessas abordagens sem observá-las caso a caso, mas a complexidade é colocada: as motivações variam entre o desejo de consciência do cidadão, o desejo de criar um vínculo social ou a necessidade de denunciar situações injustas. Essas peças às vezes estão na fronteira do ativismo e do teatro político, mas também é legítimo perguntar se há, em alguns casos, um fenômeno da moda. De qualquer forma, esse fenômeno é muito marcado na língua alemã, e muitos teatros alemães questionam cada vez mais a utilidade do teatro, seu papel político e seu lugar na sociedade. Na França, a participação de "pessoas reais" e, mais particularmente, de refugiados é mais rara, com a notável exceção da peça "81, avenida Victor Hugo", escrita por Olivier Coulon-Jablonka, Barbara Métais Chastanier e Camille Plagnet, que apresenta imigrantes sem documentado do número 81 da avenida Victor Hugo em Aubervilliers, filial em desuso de um Serviço de Emprego. Esse espetáculo teve muita repercussão na mídia e contribuiu para a regularização da maioria dos membros do grupo que se encontrava por lá.

As formas participativas aqui dizem respeito ao envolvimento de "pessoas reais" no processo de criação e não em relação à participação de espectadores durante a realização. $O$ aumento desta forma de participação no teatro parece ser uma forma de testar as questões da democracia cultural, mas também abordar diretamente as acaloradas questões políticas que atualmente dividem as populações e governos europeus. Essas práticas revelam 
mudanças claras nos modos de produção criando novos espaços dentro dos quais se desenvolvem os processos sociais e estéticos de transformação. Elas desafiam os códigos de representação, renovam as características, criam formas entre ficção e realidade, geram conhecimento e questionam a relação entre o indivíduo e o coletivo. Mas elas também colocam muitas questões éticas, que são renovadas pelo aparecimento de refugiados no palco.

\section{Ética e Estética}

Claire Bishop, em seu livro Artificell Hells, Participações Artísticas e Política de Espectáculos (Bishop, 2012), discute a complexidade das implicações éticas da arte participativa: ela observa dificuldades e divergências na forma como os projetos são avaliados, os quais são caracterizados não só pelo seu valor estético, mas também pelo impacto social concreto. Diante de projetos ambíguos, que às vezes dão mais importância aos aspectos humanos, colaborativos ou sociais do que aos aspectos estéticos, alguns críticos ou curadores incentivam e favorecem abordagens que tenham resultados concretos imediatos. Esse impacto na realidade implica, entre outras coisas, a erradicação, pelo menos parcialmente, da "marca" do artista como autor: o julgamento estético é borrado em favor de um julgamento ético. Deve-se notar que a análise se concentra em artistas oriundos das artes visuais e em um desenvolvimento iniciado na década de 1990. No entanto, Claire Bishop reabilita certas questões estéticas na abordagem de trabalhos participativos, que às vezes arriscam cair na facilidade de um diálogo consensual: "By contrast, I would argue that unease, discomfort or frustration - along with fear, contradiction, exhilaration and absurdity - can be crucial to any work's artistic impact" (Bishop, 2012, p. 26). Paul Ardenne também destaca os desenvolvimentos da arte ética, na medida em que esta arte aspirava à virada do século XXI, especialmente para uma forma de melhoria social ou política. "Neste registro, muitas vezes acontece que o artista "ético", esquecendo que ele é um homem de arte, vem deixar o território da simbolização e, dando-se em tudo ao contexto, que se faça de engenheiro de bem-estar ou solidariedade" (Ardenne, 2010, p.51-57).

Os vínculos entre questões éticas e estéticas são particularmente complexos em todas as abordagens que envolvem pessoas "reais", especialmente quando estão no palco sem ser treinadas como ator. Desejo considerar estes problemas a partir do exemplo muito singular de produção teatral nas prisões e mais particularmente através do exemplo de certos projetos realizados pelo aufBruch em Berlim. Depois de apresentar a abordagem do aufBruch, descreverei a prática que experimentei várias vezes como autora e dramaturga com o diretor Adrian Figueroa em várias prisões em Berlim.

Mesmo que sejam insuficientes, primeiro notemos que existem muitas iniciativas e práticas artísticas na prisão que estão em contextos muito diferentes. Sem fazer um inventário das políticas culturais para as pessoas que estão sob o controle da justiça, é importante observar as diferenças consideráveis entre os países, mas também dentro de um país. Os projetos artísticos nas prisões dependem em parte das decisões tomadas em um nível mais local pelas autoridades locais e muitas vezes são fruto de iniciativas singulares das associações. No sistema federal alemão, parte do quadro legislativo para a cultura está estabele- 
cida ao nível dos Länder. Além disso, a gestão das instituições penitenciárias não encoraja práticas artísticas na prisão da mesma maneira e as partes interessadas precisam se adaptar a funções diferentes de uma prisão a outra conforme, por exemplo, o ritmo dos prisioneiros e a conduta diária 5 .

A arte no ambiente da prisão está em um contexto muito específico, que consiste em abordar pessoas que são mantidas fora da sociedade. A melhoria gradual do acesso à cultura na prisão foi possível através do reconhecimento da arte como contribuição para a construção da pessoa. Jean-Louis Bernard sublinhou a respeito da criação artística e da dinâmica de integração que

"Estamos sempre em um processo de trabalho onde, através do confronto com palavras, com materiais, com o corpo de alguém, é preciso enfrentar-se a si mesmo e aos outros. Este é um trabalho real no qual os participantes sentem que, criando um objeto, um espetáculo ou um livro, eles se construirão" (Bernard, 2001, p. 10).

Muitas iniciativas para o público detido são parte da tradição de uma arte social ou são percebidas como tal, e outras, como a arte-terapia, desenvolvem práticas na encruzilhada de várias disciplinas. Além da questão da legitimidade estética dessas práticas artísticas, cujo principal objetivo seria o impacto social ou o da inserção, Patrick Champagne questiona a função do artista neste contexto, que se tornou "a figura desvalorizada do artista engajado" (Champagne, 2001, p. 38) ou endossando um "papel catalisador e revelador dos proble-

$5 \mathrm{Em}$ uma entrevista com Sybille Arndt, gerente de produção da Aufbruch em 4 de março de 2017, ela testemunha em detalhes essas diferenças de uma prisão a outra e como os ensaios devem se adaptar à cada situação específica e às regras internas de cada prisão. mas da sociedade" (Ibid, p.38). Uma vez que a prática das artes na prisão é sempre muito singular, parece pertinente observar exemplos específicos. O trabalho de aufbruch não segue a tradição de uma abordagem sociocultural. O requisito artístico é colocado antes do impacto social, o que implica um compromisso importante por parte dos prisioneiros. Pode-se formular a hipótese de que essa abordagem teria maior influência no desenvolvimento pessoal dos prisioneiros durante o encarceramento do que uma prática artística ocasional menos engajada. Em um artigo publicado no Le Monde datado de 1997, Jean-Louis Perrier observou que algumas práticas de arte nas prisões se atrevem a "tomar riscos autênticos em termos artísticos" e tem "uma capacidade de ampliar o problema sócio-cultural básico, até mesmo diferenciá-lo". O diretor Jean-Pierre Chrétien-Goni prefere observar a estética criada por essas práticas políticas de arte, em vez de ver nela uma "arte da dificuldade" (Chrétien-Goni, 2007). Além disso, as formas mencionadas acima, onde os artistas não profissionais são levados à cena, também devem ser examinados com um olho crítico em relação à qualidade estética dos espetáculos. Assim, independentemente do local de representação, as questões éticas e estéticas são indissociáveis.

\section{A prática do aufBruch}

O teatro da prisão, como a prática de aufBruch, desde 1997 (inicialmente sob a direção de Roland Brus e Holger Syrbe), em várias prisões de Berlim, é baseado em uma forma participativa. A forma como os projetos são estruturados hoje é o resultado de um desenvolvimento progressivo e fundamentado de práticas. Os 
membros permanentes da equipe, formados desde 2003 por Peter Atanassow (diretor), Holger Syrbe (cenografia e gerenciamento) e Sybille Arndt (gerente de produção), melhoraram o processo com base na experiência. Seu objetivo é obter as melhores condições de trabalho possíveis, bem como um resultado de qualidade. Eles conseguiram negociar a frequência dos ensaios, obtendo um espaço de trabalho fixo e tempo suficiente, sabendo que os internos geralmente podem se juntar aos ensaios após o trabalho de meio-tarde. Eles também observaram a importância de fortalecer a coesão do grupo, bem como a responsabilidade de cada participante no papel que ele tem a desempenhar no projeto. As peças produzidas por aufBruch envolvem a participação de presos voluntários, que, após uma média de sete semanas de ensaios, quatro dias por semana e três ou quatro horas por dia, tornam-se artistas de espetáculos de teatro. As temporadas geralmente ocorrem ao longo de duas a três semanas com uma média de três apresentações por semana e são abertas ao público externo.

As condições de trabalho procuradas pelo aufBruch são muito similares às outras produções de teatro e performance na cena artística independente na Alemanha. O aufBruch é, como qualquer outro grupo independente, solicitante de subsídios por projeto, seja ao Senado de Berlim ou a fundos concedidos às artes do espetáculo 6 . Esta possibilidade de abrir o recinto da prisão a um grande público - sob certas condições ${ }^{7}$, é uma das singularidades

6 Recentemente, o aufBruch também foi apoiado por fundos para o kulturelle Bildung, ou seja, para treinamento e educação cultural.

7 As instituições penitenciárias examinam a lista de espectadores cinco dias antes da apresentação: recusam a entrada de uma pessoa quando suspeitam que a pessoa deseja entrar na prisão por um interesse diferente do que a representação teatral, tráfico ou visita a um detido. Nem os ex-prisioneiros do trabalho de aufBruch em comparação com as dificuldades encontradas por outras iniciativas na Alemanha ou na Europa para fazer o mesmo. Embora a apresentação pública de eventos artísticos nas prisões alemãs não seja completamente inédita, Sybille Arndt explica que a particularidade do aufBruch reside na regularidade das apresentações, na profissionalização do trabalho e no acesso aos eventos ${ }^{8}$. Isso é possível hoje graças a longos anos de cooperação com as instituições carcerárias de Berlim e a confiança mútua que se desenvolveu$^{9}$. Finalmente, esta abordagem se distingue de muitos outros pelo fato de dar prioridade à exigência artística antes do desenvolvimento pessoal dos prisioneiros. Em todo caso, este trabalho não faz parte de planos oficiais de reabilitação do sistema prisional. aufBruch também não possui uma abordagem terapêutica. A principal motivação para todos os membros que intervêm na prisão (que se tratem de membros permanentes ou de colaboradores pontuais) é acreditar na singularidade, na relevância e na qualidade estética deste teatro realizado pelos detidos. O coletivo tem consciência que há, sem dúvida alguma, uma evolução pessoal positiva para os participantes, tendo que desenvolver o espírito de equipe e o senso de responsabilidade, mas isso não é explicitamente procurado nem avaliado.

À luz das questões éticas apresentadas acima, seria possível ver, ao contrário, uma forma de instrumentalização nessa abordagem. Os membros permanentes da aufBruch trabalham

têm o direito de entrar no complexo da prisão durante seis meses após sua liberação.

8 ARNDT, Sybille, 2017. Diretor de produção do aufBruch. Entrevista realizada em 4 de março de 2017, Berlim.

9 Membros do aufBruch agora podem demonstrar o reconhecimento e a importância do seu trabalho, apesar das mudanças de direção nas várias instituições. 
ao longo do ano em todas as prisões de Berlim. Eles são, portanto, pessoalmente dependentes desse trabalho, mas é também por esta razão que a qualidade do resultado é essencial. Também deve ser enfatizado que um dos objetivos do aufBruch é permitir uma reunião entre o público e os prisioneiros, quebrando o hermetismo usual da prisão. Os espectadores são levados a se questionarem sobre eventuais preconceitos sobre os prisioneiros: a qualidade do desempenho e o fato de que os prisioneiros se sentem bem em relação ao seu papel são essenciais para isso. Jens Roselt observa essa inversão em uma encenação de Peter Atanassow em 2004 na prisão de Tegel, onde os prisioneiros por sua vez observam os espectadores. Em sua descrição sobre a peça, ele enfatiza o prazer dos detentos e a confiança que eles tem na sua atuação (Roselt, 2006). Além disso, os espectadores e os detidos são geralmente convidados a trocar de papel após a peça, durante uma hora: os prisioneiros podem, nessa ocasião, ir ao seu encontro. Essa tradição permite reduzir o olhar de "voyeur" que podem ter certos espectadores.

\section{Descrição de uma prática} artística específica

Desde 2014, colaborei com aufBruch em várias prisões de Berlim sobre o desenvolvimento de duas peças, oficinas de escrita e um filme em processo de realização. Eu principalmente trabalho como autora e dramaturga com o diretor Adrian Figueroa. Desenvolvemos uma prática que corresponde a um teatro de criação, baseado em narrativas de prisioneiros e misturado com outras fontes literárias. Tratamos de temas, como a autobiografia, a memó- ria, a relação com o tempo na prisão, ou ainda entre o interior e o exterior.

A encenação de intérpretes não-profissionais coincide com uma busca de autenticidade cada vez mais marcada nas cenas contemporâneas. Annemarie Matzke enfatiza que, no momento, a onipresença da noção de autenticidade é acompanhada por dúvidas, até mesmo por um ceticismo compartilhado por todas as disciplinas. Ela também relativiza a relação entre autenticidade e espaço teatral: "A autenticidade no palco é sempre o efeito de uma construção" (Matzke, 2006) ${ }^{10}$. É com esse paradoxo que desejamos jogar explicitamente. No caso apresentado aqui, o local de representação não é um teatro, mas um lugar real, fortemente encarregado de autoridade e procedimentos. Paradoxalmente, o espaço dentro da prisão é uma área de liberdade e ficção possível. Ao trabalhar com as biografias dos prisioneiros, procuramos uma ancoragem adicional no real: a das trajetórias de vida, muitas vezes intensas, fortemente conduzidas, e a experiência compartilhada da detenção. O trabalho oscila entre autenticidade e distância com os materiais colhidos. O principal desafio é organizar elementos biográficos parcialmente ficcionalizados em uma moldura estética pertinente, sem expor os detidos. Diferentes estratégias de distanciamento em relação às narrativas dos presos são implementadas durante os estágios do processo. O desenvolvimento parcialmente fictício de narrativas reais constitui tanto um forte elemento estético de trabalho quanto um posicionamento sobre as questões éticas. É, em última análise, a ambiguidade criada na veracidade das declarações, textos e testemunhos que garante par-

10 Livremente traduzido por nós. Versão original: "Authentizität auf der Bühne ist immer Effekt einer Konstruktion." 
cialmente que os detidos sejam "protegidos".

Quanto ao processo, iniciamos os dois projetos de teatro por uma oficina de escrita ${ }^{11}$. Vários exercícios de escrita acompanhados de instruções levam os participantes a ativar elementos biográficos, lugares familiares ou pessoas, situações vividas. No entanto, nós também os encorajamos a exagerar ou a imaginar. Um exercício simples, por exemplo, é pedir aos presos que descrevam o que veem pela janela: alguns deram uma descrição muito precisa, outros descreveram o que sonhavam enquanto olhavam pela janela, outro ainda evocou os aviões que via no céu e nos quais imaginava sair da Alemanha. Além do tema da vida cotidiana no universo carcerário, tivemos diferentes oportunidades para trabalhar com as lembranças, por exemplo, pedindo que descrevessem a rua de sua infância. As restrições formais fornecem um quadro preciso dentro do qual uma força poética pode escapar: as listas inspiradas por "Espécies de Espaços", de George Perec, ou de seu livro "Eu me Lembro", onde as lembranças foram importantes fontes de inspiração. Trabalhamos também com questionários que nos permitem descobrir anedotas ou elementos de suas biografias, que podem ser atípicas ou ter um forte potencial narrativo. Isso nos permite pedir a eles que aprofundem uma história ou evento específico. No entanto, deve ser salientado que os níveis de leitura e escrita dos prisioneiros alemães são muito diferentes. Por conseguinte, preferimos em alguns casos transcrever entrevistas cujos fragmentos podem então ser integrados na montagem. Em geral, na maior parte do tempo nós usamos fragmentos como material

11 Foi parte da peça Briefe an meine Katze Bébert, em 2014, e parte da peça Zeit vergeht Warten, em 2015, ambas realizados na prisão de Plötzensee em Berlim. Eu realizei essas duas oficinas de redação com a romancista Mariana Leky. textual de peças finalizadas. Em alguns casos, parecia mais relevante para manter a cronologia de sua trajetória, a fim de compreender a sequência de certos eventos ou formas de engrenagem (em relação ao consumo ou venda de drogas, por exemplo). A escrita e as discussões às vezes nos levam a conhecer o motivo do encarceramento, mas é importante precisar aqui que nós nunca colocamos explicitamente essa questão e não tivemos acesso aos seus arquivos.

Os textos produzidos pelos detidos estão próximos do gênero literário de "autoficção", ou seja, mesmo que o autor, o narrador e o personagem sejam um, "a escrita é criadora de ficção" (Gasparini, 2008, p. 205). Além disso, muitas teorias nas ciências sociais mostram que "a verdade biográfica não é acessível"12. A construção da identidade é subjetiva e a influência dos processos de socialização intersubjetiva nesta construção deve ser levada em consideração (Berger, Luckmann, 1966). Para destacar a identidade narrativa que acompanha todas as narrativas de vida, devemos retornar mais detalhadamente ao conceito de "identidade narrativa" como desenvolve Paul Ricoeur (Ricoeur, 1990). A relação entre narrativa e ficção ocorre em diferentes níveis. No caso do nosso trabalho com as histórias contadas ou escritas pelos prisioneiros, manteremos particularmente o potencial narrativo para o devir cênico das histórias da vida. Insistimos no fato de que o homem articula suas experiências em forma de histórias, e a narrativa e a escrita tornam possível trazer a experiência completamente para a ficção. Essa "auto-intriga" da narrativa também contribui para uma

120 trabalho coletivo "Die biographische Wahrheit ist nicht zu haben", publicado por Klaus Jürgen Bruder, tem por título esta citação de Freud escrita em uma carta a Zweig, em 1939. 
melhor compreensão de si mesmo. No que diz respeito ao teatro na prisão, as apostas são duplas: a construção do eu e a produção de um discurso coletivo dentro de um ambiente cujo primeiro princípio é o isolamento (Foucault, 1975, p. 274).

Gostaria de fazer uma digressão aqui, ressaltando que alguns dos detidos que conhecemos durante nossos projetos nas prisões de Berlim realizam uma prática regular de redação sob a forma de diários, poemas e novelas. Philippe Lejeune (Lejeune, 1998) aponta que a falta de privacidade na prisão torna quase impossível qualquer forma de escrever e, especialmente, escrever autobiográfico. Chris-Bär Templiner, preso na prisão de Tegel em Berlim, atesta ${ }^{13}$ a a uma experiência contrária. Ele escreve tanto de forma autobiograficamente como ficcional (prosa e poesia) e manteve um diário íntimo por um longo tempo. E lê uma média de duas livros por semana. Helmut Kühn ${ }^{14}$ (também preso em Tegel) refere-se a uma prática similar, que também pode escrever de forma completamente livre. Esse último aliás mostra uma produtividade extrema: ele diz que escreveu cinco livros desde 2012, o que, por outro lado, reduziu sua prática como leitor. A análise de Philippe Lejeune baseia-se nas prisões francesas. As condições de encarceramento - como estar sozinho ou não em uma cela - influenciam indubitavelmente a capacidade de escrita do preso e também de participação assídua de outras atividades artísticas. Sem entrar em detalhes, os proble-

13 Chris-Bär Templiner, que foi preso por mais de trinta anos, testemunha em uma carta para mim em 5 de março de 2017 sobre suas práticas de escrita e leitura em resposta a um questionário que eu dei sobre sua prática escrita e leitura.

14 Helmut Kühn respondeu ao mesmo questionário mencionado acima em uma carta que me enviou em 13 de março de 2017. mas de saúde e superpopulação que tornam a escrita nas prisões mais difícil são mais importantes na França do que na Alemanha.

Foi interessante notar que não podemos diferenciar a verdade da falsidade nos relatos dos detidos: esse elemento devia, justamente por isso, desempenhar um papel central na nossa abordagem. O processo ético e estético deste trabalho na prisão baseia-se nesta ambiguidade, a fim de frustrar as expectativas de espectadores curiosos e até mesmo ávidos por "confissões lascivas". Louis Patrick Leroux descreve esse fenômeno da seguinte forma: "A chamada confissão lasciva é muitas vezes ligada a um trauma, a uma confissão por parte do ator: homossexualidade, doença, comportamento que ele reprova. É um testemunho íntimo que permite ao ator/autor exorcizar uma problemática que o dominou. (Leroux, 2004, p. 79). Ele continua a salientar que "a confissão lasciva incomoda uma parte do público por sua natureza exibicionista e alimenta o interesse de outros espectadores" (Ibid, p.79). É impossível evitar completamente a busca do sensacionalismo de certos membros da plateia e a confissão (lasciva) de certos detidos, mas diferentes estratégias permitem atenuar essa relação, porque isso parece justamente problemático ao nível ético e estético. Observamos também que a passagem para a cena permite uma forma de distanciamento adicional em relação às fontes referenciais.

Mas voltemos às diferentes etapas do processo criativo. O material coletado é montado, os textos são condensados e cortados. Os materiais escolhidos são então reintegrados em uma montagem, isto é, em uma "nova cadeia de significados" (Piemme, 2011). Também introduzi textos literários emprestados, entre outros, de Ferdinand Céline, Virginie Despentes, 
Max Frisch ou ainda Sarah Kane aos textos dos detentos. Isso permitia acentuar a confusão, descrita acima, quanto à veracidade das declarações dos detidos. A peça constituída por uma colagem de textos evolui ainda à medida que os ensaios progridem e os textos memorizados pelos prisioneiros são submetidos à prova da teatralidade da cena. Uma equipe de atores não penitenciários, que são artistas profissionais, participa da segunda fase do trabalho: durante os ensaios, eles criam música, figurinos ou vídeos (o que desempenhou um papel importante em duas produções em Plötzensee). Não se trata aqui de descrever em detalhes esses estágios, mas de especificar que a abordagem estética não é crua ou minimalista. Pelo contrário, concede-se importância aos aspectos visuais e sonoros das apresentações. Na peça Zeit vergeht Warten (2015), uma parte da cenografia consistiu em um fundo verde diante do qual os artistas às vezes chegavam a falar na frente de uma câmera, enquanto a imagem era retransmitida em outro lugar no espaço do palco, com projeções de vídeo. Esse processo de duplicação permitia ver a projeção do intérprete em outro lugar, em outro contexto, e simultaneamente, sua presença real no palco. Acrescentamos a isso que certos processos performativos contribuíram nas duas encenações para quebrar um pouco mais as barreiras entre "o exterior e o interior". Na peça Briefe an meine katze Bébert (2014), uma câmera foi instalada em uma sala adjacente à sala de apresentação. Durante uma cena, alguns espectadores voluntários foram convidados a fumar um cigarro com alguns detidos neste espaço, enquanto a ação que estava ocorrendo era transmitida ao vivo no palco principal. Outra originalidade: em ambos os espetáculos (de 2014 e 2015), um preso cozinhava cena durante toda representação e a refeição era servida ao público, convidado a permanecer após a sessão.

Assim, a autenticidade de certos textos misturava-se com a teatralidade dos outros elementos da atuação, bem como com certos aspectos performativos. A transição para o palco brevemente descrita aqui é, portanto, uma etapa importante em que as narrativas escritas pelos prisioneiros são parte de um dispositivo teatral e de um processo criativo coletivo.

O essencial deste trabalho consiste, de um lado, em empregar o que são, para ser mais preciso, a forma como eles se percebem, mas também os personagens que eles criaram, o que eles gostariam de ser ou ainda os mundos fantásticos ou imaginários que às vezes cultivam. Por outro lado, trata-se também, através da edição dos textos e da encenação, do que projetamos sobre eles, da maneira como os percebemos.

Nesta discrepância das percepções, aparece uma tensão que é constantemente questionada e reajustada, já que este tipo de criação nunca está congelada. Esse processo de ida e volta difere de muitas abordagens autobiográficas para o teatro, como aquelas em que o próprio autor se coloca em cena. Conforme abordamos acima, as atuais práticas documentais, colocando em cena por exemplo "especialistas do cotidiano" como refugiados, correspondem a abordagens sempre particulares que diferem muito, umas das outras, pela maneira como elas representam a sociedade e suas implicações políticas. O teatro na prisão se inscreve numa tradição de dar voz aos que não a tem, refletindo a diversidade da sociedade e encorajando a emancipação de cada um através do idioma e da arte, como Augusto Boal e Armand Gatti experimentaram (apesar 
de suas diferenças). O deslocamento do local teatral também reforça a utilidade do teatro em sua ancoragem no real e no presente afirmando seu papel como espaço agonístico.

A maneira de trabalhar, envolver e incluir os participantes em um projeto é essencial em relação às questões éticas que surgem com a criação de intérpretes não-profissionais. Essas experiências realizadas na prisão revelam a importância dessas questões, pois o contexto de prisão aumenta a vulnerabilidade dos participantes. O risco de expô-los é muito mais forte porque se trata de uma moldura disciplinar na qual o poder é exercido sobre corpos e mentes, para citar Foucault:

"A prisão deve ser um microcosmo de uma sociedade perfeita em que os indivíduos estão isolados em sua existência moral, mas onde sua união ocorre em um quadro hierárquico rigoroso, sem relação lateral, sendo possível a comunicação apenas no sentido vertical" (Foucault, 1975, p.276).

É por isso que o espaço de expressão criado por esses projetos, que dá liberdade de expressão aos detidos em comunicação com participantes fora do sistema judicial e prisional (sem objetivos terapêuticos, pedagógicos ou de reintegração per si), parece ser extremamente precioso. É muito importante deixar claro aos prisioneiros que sua participação no projeto não lhes permitirá necessariamente reduzir sua sentença. Não fazer falsas promessas: eis o que parece essencial, especialmente no contexto particular do universo prisional e na privação da liberdade. Em geral, esta devia ser a regra em todos os casos em que "pessoas reais" estão envolvidas em um projeto artístico. Por outro lado, o fato de que os amadores não estão necessariamente conscientes da imagem que se tem deles é um problema frequentemente levantado sobre peças que retratam "pessoas reais". Essa questão reforça a responsabilidade da equipe artística que traz o projeto. Nossa posição em relação a isso (que é uma resposta possível entre outros) é a criação de uma troca que se aproxima da abordagem das "imagens negociadas" do fotógrafo Michel Séméniako, que realiza retratos em consulta com seus sujeitos. O filme Anderswo, que está em processo de realização, é inspirado por esta prática em que a arte intervém na realidade e onde a realidade intervém nas imagens artísticas.

O enquadramento espaço-temporal constitui a especificidade da representação teatral. A dissolução do tempo e o espaço confinado da prisão estão no centro da experiência da prisão. O teatro e a prisão são lugares "absolutamente diferentes", "lugares heterotópicos" (Foucault, 2009, (1966)). Lugares abertos ou fechados, mas "que os isola do espaço circundante" (Foucault, 2009, (1966) p.32). Qual papel o teatro pode desempenhar na prisão? "Acontece que as heterotopias são mais frequentemente ligadas a cortes de tempo singulares" (Ibid, p. 30). E como se pode entender a relação com o corpo quando estes espaços - tempos de encarceramento e representação são misturados? "Ele [o corpo] está no coração do mundo este pequeno núcleo utópico do qual eu sonho, eu falo, avanço, imagino, percebo coisas em seu lugar e eu os nego também pelo poder indefinido das utopias que eu imagino" (Ibid, p.18). Quando as pessoas estão trancadas por longos períodos de tempo, elas percebem o papel vital que a música, a leitura ou a escrita podem desempenhar em suas vidas diárias. $\mathrm{O}$ corpo só escapa simbolicamente pela imaginação. As experiências teatrais realizadas até agora e o filme em desenvolvimento nos per- 
mitiram uma forma de trabalhar no ambiente da prisão (que permanece inseparável do seu contexto de produção na Alemanha, em Berlim e com o aufBruch): o fruto de uma troca que oscila entre o testemunho real e o criação de imagens poéticas". A imaginação em suas ações vivas nos separa do passado e da realidade (Bachelard, 2009, (1957), p.16). No entanto, a realidade das histórias de vida dos prisioneiros possui uma força narrativa inegável, pois suas histórias são às vezes marcadas pelo exílio, violência, solidão, fuga, culpa ou ainda estão tensionadas entre um relacionamento hedonista no momento presente e razoável no futuro. Suas narrativas e as imagens poéticas da criação artística na prisão parecem ilustrar enfaticamente o que "o materialismo da ficção experimenta no irreal da realidade, enquanto que o inacreditável do real encontra seu equivalente apenas na ficção" (Pic, 2010). Imagens reais e simbólicas e a ambiguidade entre real e ficcional revelam um espaço poético. Enfim, as formas de sociabilidade criadas através desta abordagem (bem como outras práticas intervencionistas em arte), juntamente com as questões éticas transmitidas, refletem novas práticas políticas na arte, nas quais os aspectos sociais, estéticos e simbólicos são inseparáveis.

\section{References}

ARDENNE, Paul, L'avenir éthique de l'art. Nouvelle revue d'esthétique, 2/2010. $N^{\circ} 6$, (p. 51-57). [URL: http://www.cairn.info/revue-nouvelle-revue-d-esthetique-2010-2-page-51. htm], (page consultée le 3 mars 2017).
BACHELARD, Gaston. La poétique de l'espace. Paris: Presses universitaires de France, 2009 (1957).

BERNARD, Jean-Louis. Introduction. In: BERNARD, Jean-Louis (coord). La création artistique et collective au cœur de la dynamique d'insertion.Budapest; Torino: I'Harmattan, 2001.

BISHOP, Claire. Artificell hells, Participatory Art and the Politics of Spectatorship.London, New York : Verso, 2012.

CHAMPAGNE, Patrick. Digression autour des fonctions de l'art. In : BERNARD, Jean-Louis (Coord.). La création artistique et collective au cœur de la dynamique d'insertion.Budapest ; Torino : I'Harmattan, 2001. (p.37-44).

CHRÉTIEN-GONI, Jean-Pierre. Artistes in extremis. In : Les hors-champs de l'art. Prisons, psychiatrie, quelles actions artistiques ? Cassandre/Horschamp, 2007. (p.187-196).

DANAN, Joseph. Entre théâtre et performance. Arles : Actes Sud, 2016.

FOUCAULT, Michel. Le corps utopique, les hétérotopies. France : Nouvelles Editions Lignes, 2009 (1966).

FOUCAULT, Michel. Surveiller et punir, Naissance de la prison. Paris : Gallimard, 1975.

GASPARINI, Philippe. Autofiction,Une aventure du langage. Paris : Seuil, 2008.

LEJEUNE, Philippe. Ecrire à l'ombre 1 et Ecrire à l'ombre 2. In: Pour l'autobiographie, Chroniques. Paris: Seuil, 1998. (p.104-112).

LEROUX, Louis Patrick. Théâtre autobiographique: quelques notions. In : La tentation biographique. Jeu: revue de théâtre, $n^{\circ} 111$, (2) 2004. Consultable en ligne: http://id.erudit. org/iderudit/25505ac, (page consulté le 14 avril 2017). (p.75-85). 
MATZKE, Annemarie. Von echten Menschen und wahren Performern. In: FISCHER-LICHTE Erika, GRONAU, Barbara (Coord.), Wege der Wahrnehmung, Authentizität, Reflexivität und Aufmerksamkeit im zeitgenössischen Theater. Berlin: Theater der Zeit, Recherche 33, 2006. (p.39-47).

PERRIER, Jean-Louis. Le monde carcéral s'ouvre à la pratique des arts. Le Monde, Samedi 22 mars 1997.

PIC, Muriel. W.G. Sebald. Les patiences de la mémoire. In: CRIQUI, Jean-Pierre (Coord.). L'image document, entre réalité et fiction. Paris: Les carnets du bal \#1, Le Bal / Images en manœuvres éditions, 2010. (p.92-119).

PIEMME, Jean-Marie. Fiction toujours. In: PIEMME, Jean-Marie, LEMAIRE, Véronique (Coord.). Usages du « document », Les écritures théâtrales entre réel et fiction. Louvain-la-Neuve: Etudes théâtrales 50, 2011. (p.93).

ROSELT, Jens, Die Arbeit am Nicht-Perfekten. In: FISCHER_LICHTE, Erika, GRONAU, Barbara (Coord.). Wege der Wahrnehmung: Authentizität, Reflexivität und Aufmerksamkeit im zeitgenössichen Theater. Berlin: Theater der Zeit, Recherche 33, 2006. (p.28-38).

RICOEUR, Paul. Soi-même comme un autre, Paris: Le Seuil, 1990.

Tradução de Clóvis D. Massa 